\title{
Fault Detection of Inline Reciprocating Diesel Engine: A Mass and Gas-Torque Approach
}

\author{
S. H. Gawande, ${ }^{1}$ L. G. Navale, ${ }^{1}$ M. R. Nandgaonkar, ${ }^{2}$ D. S. Butala, ${ }^{3}$ and S. Kunamalla ${ }^{3}$ \\ ${ }^{1}$ Department of Mechanical Engineering, M. E. Society's College of Engineering, Pune-411 001, Maharashtra, India \\ ${ }^{2}$ Department of Mechanical Engineering, Government College of Engineering, Pune-411 005, Maharashtra, India \\ ${ }^{3}$ Research and Development, Greaves Cotton Limited, Pune-411 019, Maharashtra, India \\ Correspondence should be addressed to S. H. Gawande, shgawande@yahoo.co.in
}

Received 6 April 2012; Revised 12 July 2012; Accepted 15 July 2012

Academic Editor: Abul Azad

Copyright (๑) 2012 S. H. Gawande et al. This is an open access article distributed under the Creative Commons Attribution License, which permits unrestricted use, distribution, and reproduction in any medium, provided the original work is properly cited.

\begin{abstract}
Early fault detection and diagnosis for medium-speed diesel engines are important to ensure reliable operation throughout the course of their service. This work presents an investigation of the diesel engine combustion-related fault detection capability of crankshaft torsional vibrations. Proposed methodology state the way of early fault detection in the operating six-cylinder diesel engine. The model of six cylinders DI Diesel engine is developed appropriately. As per the earlier work by the same author the torsional vibration amplitudes are used to superimpose the mass and gas torque. Further mass and gas torque analysis is used to detect fault in the operating engine. The DFT of the measured crankshaft's speed, under steady-state operating conditions at constant load shows significant variation of the amplitude of the lowest major harmonic order. This is valid both for uniform operating and faulty conditions and the lowest harmonic orders may be used to correlate its amplitude to the gas pressure torque and mass torque for a given engine. The amplitudes of the lowest harmonic orders $(0.5,1$, and 1.5$)$ of the gas pressure torque and mass torque are used to map the fault. A method capable to detect faulty cylinder of operating Kirloskar diesel engine of SL90 Engine-SL8800TA type is developed, based on the phases of the lowest three harmonic orders.
\end{abstract}

\section{Introduction}

The great interest of engine manufacturing industry and research centers on the crankshaft vibration [1] and instantaneous speed analysis for the fault or misfire detection in internal combustion engines is due to the positive results obtained using different approaches. A misfire event can be considered as an impulsive excitation on the crankshaft, related to the lack of torque resulting from the missing combustion. This excitation causes a sudden engine speed decrease followed by an oscillation with characteristics amplitude and frequency associated with the torsional behavior of the engine-load system.

A number of methods are devised to detect nonuniformities in the contributions of the cylinders to the total engine output by analyzing the variation of the measured crankshaft's speed may be classified in different groups such as observer-based method, pattern recognition, statistical estimators, order domain methods, and a combination of these methods. In [2], a good overview of the earlier state of the art has been presented. The model developed in [3] has been extensively used with very good results to predict and control torsional vibrations to correlate the amplitudes of the major harmonic orders of the crankshaft's speed variation with the average indicated mean effective pressure of the engine. Balancing the cylinder-wise torque contributions of automotive and other high-speed engines is usually addressed by reconstructing the cylinder-wise netindicated torques, by direct use of the angular acceleration [4]. The method suggested $[5,6]$, in which the measured angular speed was directly related to the nonuniform torque contribution to detect misfire. In order to determine the cylinder-wise net-indicated torque, the oscillating torque applied on the flywheel was reconstructed from measurements of the angular speeds of the crankshaft. The oscillating torque can be reconstructed by using a single mass engine model and one angular speed measurement [7] by assuming that the crankshaft is rigid and that the engine is sufficiently 
decoupled from the transmission and load,. Obtaining an estimate of the prevailing load torque $[7,8]$ uses the fact that the instantaneous torque from the engine is zero at topdead center (TDC) and bottom-dead-center (BDC). In [9], misfire was simulated by disconnection of fuel supply of one cylinder of the engine which describes the measurements of vibro-acoustic exhaust locomotive engine signals for misfire phenomenon simulation and some results of their nonlinear analysis. Instead of estimating the engine load torque [10] proposed an observer-based method, which uses the measured engine load torque directly to reconstruct the cylinderwise net-indicated torques of a six-cylinder engine. In [11], a novel method, based on the polar coordinate system of the instantaneous angular speed (IAS) waveform, has also been introduced: to improve the discrimination features of the faults compared to the FFT-based approach of the IAS signal. In [11], two typical experimental studies were performed on 16- and 20-cylinder engines, with and without faults, and diagnose the results by the proposed polar presentation method. Method for evaluating the torque nonuniformity between the various cylinders of an internal combustion engine due to statistical dispersion in manufacturing or aging in the injection system is proposed in [12], where the problem of the crankshaft torsional vibration effects is presented on the engine speed fluctuations, that make the misfire detection critical, when multiple misfires are present in the same cycle. In [13], a simple algorithm based on an energy model of the engine which requires the measurement of the instantaneous angular speed for misfire detection in reciprocating engines is proposed. By processing the engine dynamics in the angular domain, variations in the working parameters of the engine, such as external load and mean angular speed, are compensated. A dimensionless feature has been abstracted for evaluation of the combustion as well as compression process of each cylinder.

In this work, a method of detecting early fault for medium-speed power plant diesel engines is proposed, in which as in $[14,15]$ torsional vibration amplitudes are used to superimpose the mass and gas torque. Further mass and gas torque analysis is used to detect fault in the operating engine.

\section{Problem Definition}

Problem studying in this work is to identify the early faulty cylinder by using the amplitudes of torsional vibration and lowest harmonic orders $(0.5,1$, and 1.5$)$ of the inertia masses and DFT of measured engine speed signal based on gas forces. In this paper, the authors focus and present how amplitudes of torsional vibration play an important role in performance diagnosis of internal combustion engine which will be the recent area of research for engine manufacturing industry and research centers.

\section{Engine Model}

Figure 1 illustrates a complete mass-elastic model of a fourstroke six-cylinder inline diesel engine system. There is a flywheel on the engine shaft to even the rotational speed of
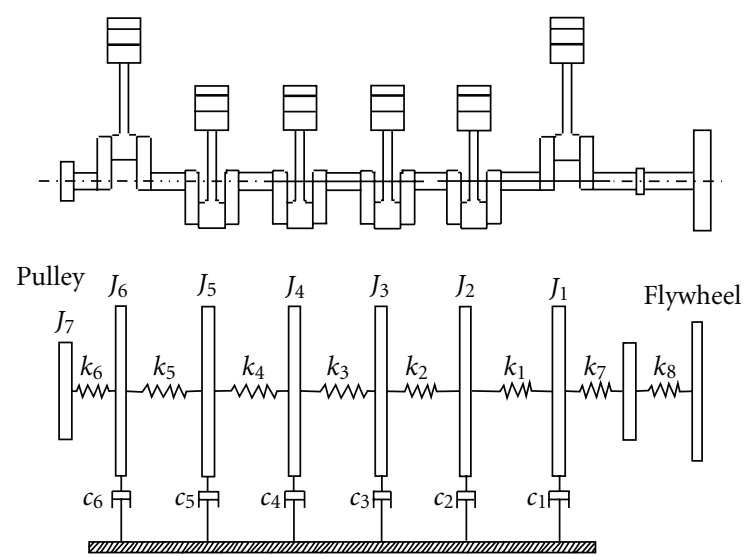

Figure 1: - Mass-elastic model of a four-stroke six-cylinder inline diesel engine.

the engine shaft. The rectangles in Figure 1 represent masses with link rotating in relation to the shafts. For example, the mass of the piston/crank mechanism of each cylinder is illustrated by rectangles. Dampings are represented by the box/plate symbol and stiffness of shafts is represented by spring symbol. In Figure $1, J_{1}, \ldots, J_{7}$ are the inertia of the each cylinder and pulley, $k_{1}, \ldots, k_{8}$ are the stiffness, and $c_{1}, \ldots, c_{6}$ are the viscous damping's, respectively.

\section{Results and Discussion}

In this work, as per $[1,6,14,15]$, detailed torsional vibration analysis was carried out and is used to calculate the torsional vibration amplitude for the given operating engine. The information in Table 1 pertains to the four-stroke, sixcylinder inline diesel engine. Tables 2, 3, and 4 show detailed torsional vibration analysis for the engine under consideration.

\section{Interpretation and Calculation of Resultant Phase Vector Based on Reciprocating Masses}

Here, the engine under consideration is SL90 model manufactured by Kirloskar Oil Engine Pune-03. For the considered six-cylinder engine used as an example, the crankshaft has crank throws spaced $120^{\circ}$ apart. The firing sequence selected is 1-5-3-6-2-4. Considering the order number is the number of complete cycles occurring during one crankshaft revolution, and then the first-order vectors will be spaced $120^{\circ}$ apart in the sequence corresponding to the firing order. second-order vectors rotate at twice crank intervals so each succeeding second-order vector will be spaced at $2 \times 120^{\circ}=$ $240^{\circ}$ apart in their correct sequence and so on.

5.1. Torsional Resonance Calculation by Holzer Tabulation Method. A phase vector diagram as shown in Figure 2 is drawn for torsional resonance of $1387.22 \mathrm{rpm}$ for the given engine to analyze the minor and major critical harmonic orders. It is seen that the third order is the major critical 


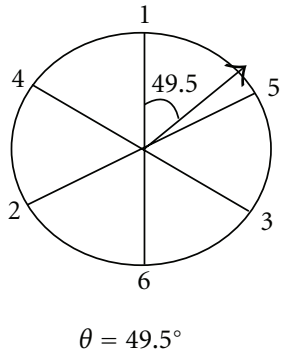

(a)

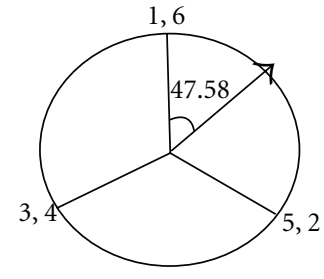

$\theta=47.58^{\circ}$

(b)

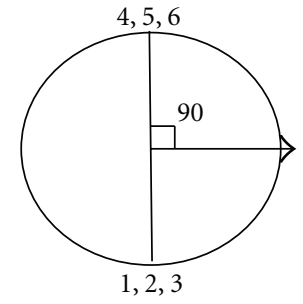

$\theta=90^{\circ}$

(c)

Figure 2: Phase vector diagram for $0.5,1,1.5$ order.

TABLE 1: Engine basic data.

\begin{tabular}{|c|c|c|}
\hline \multicolumn{2}{|c|}{ Engine type } & Inline, four stroke, DI \\
\hline \multicolumn{2}{|c|}{ Number of cylinder } & 6 \\
\hline \multicolumn{2}{|c|}{ Direction of rotation } & Anticlockwise \\
\hline \multicolumn{2}{|c|}{ Firing order } & $1-5-3-6-2-4$ \\
\hline \multicolumn{2}{|c|}{ Power output at $1500 \mathrm{rpm}$} & 309 H.P \\
\hline \multicolumn{2}{|c|}{ Cylinder diameter } & $118 \mathrm{~mm}$ \\
\hline \multicolumn{2}{|c|}{ Piston stroke } & $135 \mathrm{~mm}$ \\
\hline \multicolumn{2}{|c|}{ Compression ratio } & 15.5 \\
\hline \multicolumn{3}{|c|}{ Engine mass-elastic system } \\
\hline \multirow{2}{*}{ Mass } & Inertia & Stiffness \\
\hline & $\mathrm{Kg} \mathrm{m}^{2}$ & $\mathrm{MN} \mathrm{m} / \mathrm{rad}$ \\
\hline Pulley & 0.094 & 0.391 \\
\hline Cyl.1 & 0.075 & 1.952 \\
\hline Cyl.2 & 0.075 & 1.952 \\
\hline Cyl.3 & 0.075 & 1.952 \\
\hline Cyl.4 & 0.075 & 1.952 \\
\hline Cyl.5 & 0.075 & 1.952 \\
\hline Cyl.5 & 0.075 & 1.952 \\
\hline Cyl.6 & 0.075 & 3.52 \\
\hline Flywheel & 1.97 & \\
\hline
\end{tabular}

orders of excitation for calculated torsional resonance. The corresponding critical speeds of engine operation would be;

$$
\begin{aligned}
& =1148 \mathrm{vpm} / 3=191.330 \mathrm{rpm} \\
& =2379 \mathrm{vpm} / 3=396.500 \mathrm{rpm} \\
& =4162 \mathrm{vpm} / 3=1387.33 \mathrm{rpm} \Leftarrow
\end{aligned}
$$

Since the 3rd order excitation of 3-node vibration mode falls within the operating range of 750 to $2200 \mathrm{rpm}$, hence a phase vector diagram as shown in Figure 2 is drawn for torsional resonance of $1387.33 \mathrm{rpm}$ or $4162 \mathrm{vpm}$ (Vibration per Minute).

Figures 2(a) and 2(b) shows the phase angle diagram with resultant vectors for the 0.5 order and 1 order with phase angles $60^{\circ}$ and $120^{\circ}$. The cylinder number and the amplitude vectors corresponding to it are shown in Figure 2 are drawn by using data in Table 5 . It is found that more than one vector has the same angular position, so these have been arithmetically added making the diagram to the right. Then, by taking cosine components and algebraically adding the total cosine (vertical) component for the resultant vector is found, and by taking the sine components the resultant sine component is similarly found. The resultant vector magnitude is then

$$
\begin{aligned}
{\text { Resultant Vector }]^{2}=} & {[\text { Sine Component }]^{2} } \\
& +[\text { Cosine Component }]^{2} .
\end{aligned}
$$

It is found that the fourth-order successive vectors are spaced at $4 \times 120=480^{\circ}=\left(360+120^{\circ}\right)$ apart and, therefore, have the same pattern as for the first order, similarly for the 7 th and 10th orders. Figure 2(a) shows the 0.5, 2.5, 3.5, 5.5, 6.5 orders. The 1.5, 4.5, 7.5 orders as shown in Figure 2(c) all act up and down, as drawn, and have a moderately large resultant. In the case of order numbers which are multiples of half the number of cylinders, that is, 3, 6, 9, and so forth, for the considered six-cylinder engine, all the vectors act in the same direction (not shown in Figure 2), for this reason, they are called "Major Orders."

For 0.5 Order. Phase vector angle, $\theta=\tan ^{-1}$ (sum of all vertical components/sum of all horizontal components) $\theta=$ $-49.50^{\circ}$.

For 1 Order. Phase vector angle, $\theta=\tan ^{-1}$ (sum of all vertical components/sum of all horizontal components) $\theta=$ $-47.58^{\circ}$.

For 1.5 Order. Phase-vector angle $\theta=\tan ^{-1}$ (sum of all vertical components/sum of all horizontal components) $\theta=$ $90^{\circ}$.

For given engine the resultant phase vector can be calculated as above, and this Resultant phase Vector can be represented (by arrow having magnitude equal to amplitude of torsional vibration) as in Figures 2(a), 2(b), and 2(c).

\section{Interpretation and Calculation of Resultant Phase Vector Based on Gas Forces}

Extensive experiments were conducted on a four-stroke six cylinder direct injection diesel engine (Kirloskar SL90SL8800TA). The engine was operated at constant speed and 
TABLE 2: Natural frequency of whole system $=1148 \mathrm{vpm}$.

\begin{tabular}{|c|c|c|c|c|c|c|c|c|}
\hline & \multirow[t]{2}{*}{ Mass no. } & $\begin{array}{c}\text { Moment } \\
\text { of inertia } \\
J\end{array}$ & $\begin{array}{l}\text { Torque per unit } \\
\text { deflection } \\
J \omega^{2}\end{array}$ & $\begin{array}{c}\text { Deflection in plane } \\
\text { of mass } \\
\theta\end{array}$ & $\begin{array}{c}\text { Torque in plane } \\
\text { of mass } \\
J \omega^{2} \theta\end{array}$ & $\begin{array}{l}\text { Total torque } \\
\qquad \Sigma J \omega^{2} \theta\end{array}$ & $\begin{array}{c}\text { Shaft stiffness } \\
C\end{array}$ & $\begin{array}{l}\text { Change in } \\
\text { deflection } \\
\quad \Delta \theta\end{array}$ \\
\hline & & $\mathrm{Kg} \mathrm{m}^{2}$ & $\mathrm{MN} \mathrm{m}$ & $\pm \mathrm{rad}$ & $\mathrm{MN} \mathrm{m}$ & $\mathrm{MN} \mathrm{m}$ & $\mathrm{MN} \mathrm{m} / \mathrm{rad}$ & $\mathrm{rad}$ \\
\hline Pulley & 1 & 0.094 & 0.1238829 & 1 & 0.123882976 & 0.123882976 & 0.391 & 0.31683626 \\
\hline Cyl.1 & 2 & 0.075 & 0.0988428 & 0.683163744 & 0.067525817 & 0.191408793 & 1.952 & 0.09805778 \\
\hline Cyl.2 & 3 & 0.075 & 0.0988428 & 0.585105961 & 0.057833511 & 0.249242305 & 1.952 & 0.12768561 \\
\hline Cyl.3 & 4 & 0.075 & 0.0988428 & 0.457420354 & 0.045212709 & 0.294455013 & 1.952 & 0.15084786 \\
\hline Cyl.4 & 5 & 0.075 & 0.0988428 & 0.306572499 & 0.030302484 & 0.324757498 & 1.952 & 0.16637167 \\
\hline Cyl.5 & 6 & 0.075 & 0.0988428 & 0.14020083 & 0.013857843 & 0.33861534 & 1.952 & 0.17347097 \\
\hline Cyl.6 & 7 & 0.075 & 0.0988428 & -0.03327014 & -0.00328851 & 0.335326826 & 3.52 & 0.0952633 \\
\hline Flywheel & 8 & 1.97 & 2.5962708 & -0.12853344 & -0.33370764 & 0.001619182 & & \\
\hline & & & & $F=1148 \mathrm{vpm}$ & bration per min.) & & & \\
\hline
\end{tabular}

TABLE 3: Natural frequency of whole system $=2379 \mathrm{vpm}$.

\begin{tabular}{|c|c|c|c|c|c|c|c|c|}
\hline & \multirow[t]{2}{*}{ Mass no. } & $\begin{array}{l}\text { Moment of } \\
\text { inertia } \\
J\end{array}$ & $\begin{array}{l}\text { Torque per unit } \\
\text { deflection } \\
J \omega^{2}\end{array}$ & $\begin{array}{c}\text { Deflection in plane } \\
\text { of mass } \\
\theta\end{array}$ & $\begin{array}{c}\text { Torque in plane } \\
\text { of mass } \\
J \omega^{2} \theta\end{array}$ & $\begin{array}{l}\text { Total torque } \\
\qquad \Sigma J \omega^{2} \theta\end{array}$ & $\begin{array}{c}\text { Shaft stiffness } \\
C\end{array}$ & $\begin{array}{c}\text { Change in } \\
\text { deflection } \\
\Delta \theta\end{array}$ \\
\hline & & $\mathrm{Kg} \mathrm{m}^{2}$ & $\mathrm{MN} \mathrm{m}$ & $\pm \mathrm{rad}$ & MN m & $\mathrm{MN} \mathrm{m}$ & $\mathrm{MN} \mathrm{m} / \mathrm{rad}$ & $\mathrm{rad}$ \\
\hline Pulley & 1 & 0.094 & 0.5320062 & 1 & 0.532006254 & 0.532006254 & 0.391 & 1.36062981 \\
\hline Cyl.1 & 2 & 0.075 & 0.4244730 & -0.36062981 & -0.15307764 & 0.378928611 & 1.952 & 0.19412326 \\
\hline Cyl.2 & 3 & 0.075 & 0.4244730 & -0.55475307 & -0.23547774 & 0.14345087 & 1.952 & 0.07348918 \\
\hline Cyl.3 & 4 & 0.075 & 0.4244730 & -0.62824225 & -0.26667192 & -0.12322105 & 1.952 & -0.0631255 \\
\hline Cyl.4 & 5 & 0.075 & 0.4244730 & -0.56511671 & -0.23987683 & -0.36309787 & 1.952 & -0.1860133 \\
\hline Cyl.5 & 6 & 0.075 & 0.4244730 & -0.37910345 & -0.16091922 & -0.52401708 & 1.952 & -0.2684514 \\
\hline Cyl.6 & 7 & 0.075 & 0.4244730 & -0.11065208 & -0.04696883 & -0.57098591 & 3.52 & -0.1622119 \\
\hline \multirow[t]{2}{*}{ Flywheel } & 8 & 1.97 & 11.149492 & 0.051559828 & 0.574865928 & 0.003880017 & & \\
\hline & \multicolumn{8}{|c|}{$F=2379$ vpm (vibration per min.) } \\
\hline
\end{tabular}

full loads. To simulate a early faulty cylinder, the engine was operated under normal working condition. The pressures were measured in all cylinders by piezoelectric pressure transducers. The mean-indicated pressure (MIP) and the gas pressure torque (GPT) of each cylinder were calculated from the pressure traces. The GPT and the measured speed were subjected to a discrete Fourier transform (DFT) to determine the amplitudes and phases of their harmonic components. Figure 3 shows an actual pressure curve generated by the pressure transducers on all six cylinders when engine was working under normal condition. The results of the application of this technique to given DI Diesel engine are graphically shown in Figures 4 and 5.

It is observed that when the cylinders are uniformly contributing to the total engine torque, the first three harmonic orders $(K=0.5,1,1.5)$ play a significant role in the frequency spectrum of the total gas-pressure torque and, consequently, appear with a very low contribution in the frequency spectrum of the crankshaft's speed $[5,6]$. If the frequency spectrum of the crankshaft's speed corresponding to uniform cylinders operation is compared to the spectrum corresponding to a faulty cylinder, one may see that the major difference is produced by the amplitudes of the first three

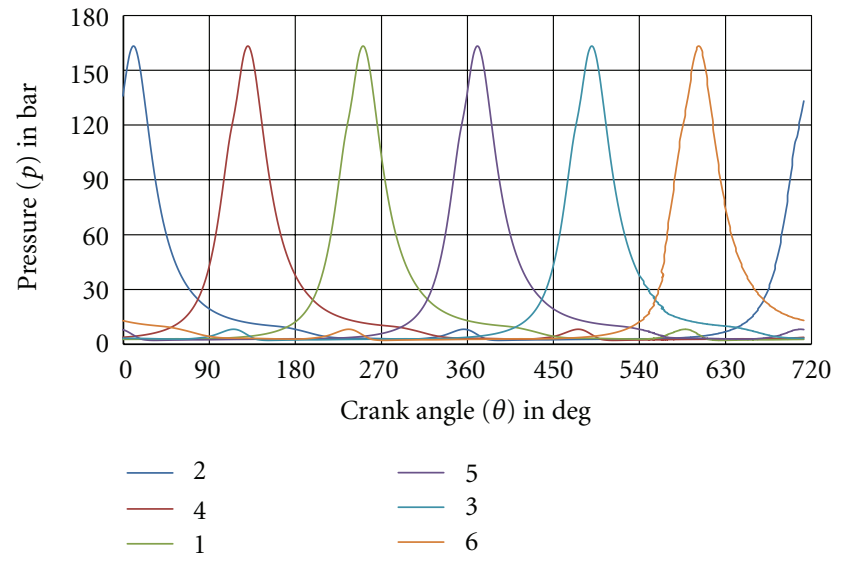

FIGURE 3: Gas pressure versus crank angle.

harmonic orders. As far as the cylinders operate uniformly, these amplitudes are maintained under a certain limit. Once a cylinder starts to reduce its contribution, the amplitudes of the first three harmonic orders start increasing. These amplitudes may be used to determine the degree by which 
TABLE 4: Natural frequency of whole system $=4162 \mathrm{vpm}$.

\begin{tabular}{|c|c|c|c|c|c|c|c|c|}
\hline & \multirow[t]{2}{*}{ Mass no. } & $\begin{array}{c}\text { Moment of } \\
\text { inertia } \\
J\end{array}$ & $\begin{array}{l}\text { Torque per unit } \\
\text { deflection } \\
J \omega^{2}\end{array}$ & $\begin{array}{l}\text { Deflection in } \\
\text { plane of mass } \\
\theta\end{array}$ & $\begin{array}{l}\text { Torque in plane } \\
\text { of mass } \\
J \omega^{2} \theta\end{array}$ & $\begin{array}{l}\text { Total torque } \\
\qquad \Sigma J \omega^{2} \theta\end{array}$ & $\begin{array}{c}\text { Shaft stiffness } \\
\text { C }\end{array}$ & $\begin{array}{l}\text { Change in } \\
\text { deflection } \\
\quad \Delta \theta\end{array}$ \\
\hline & & $\mathrm{Kg} \mathrm{m}^{2}$ & $\mathrm{MN} \mathrm{m}$ & $\pm \mathrm{rad}$ & $\mathrm{MN} \mathrm{m}$ & $\mathrm{MN} \mathrm{m}$ & $\mathrm{MN} \mathrm{m} / \mathrm{rad}$ & $\mathrm{rad}$ \\
\hline Pulley & 1 & 0.094 & 2.016259 & 1 & 2.016259 & 2.016259 & 0.391 & 0.974415 \\
\hline Cyl.1 & 2 & 0.075 & 0.07293367 & -3.164426946 & 0.018660 & 2.034920 & 1.952 & 0.914119 \\
\hline Cyl.2 & 3 & 0.075 & 0.07293367 & -1.8924842 & -0.648040 & 1.386879 & 1.952 & 0.623009 \\
\hline Cyl.3 & 4 & 0.075 & 0.07293367 & 0.639015657 & -1.102423 & 0.2844561 & 1.952 & 0.127782 \\
\hline Cyl.4 & 5 & 0.075 & 0.07293367 & 2.745213832 & -1.195620 & -0.911163 & 1.952 & -0.40931 \\
\hline Cyl.5 & 6 & 0.075 & 0.07293367 & 3.024314267 & -0.897095 & -1.808259 & 1.952 & -0.81235 \\
\hline Cyl.6 & 7 & 0.075 & 13.164734 & 1.290559567 & 2.125865 & 0.01295095 & 3.52 & 0.161948 \\
\hline Flywheel & 8 & 1.97 & 27.805941 & -0.147208403 & -0.0129509 & $0.03691 E-6$ & & \\
\hline & & & & $F=4162 \mathrm{vpm}$ & bration per min. & & & \\
\hline
\end{tabular}

TABle 5: Summary of the values of torsional vibration amplitude from Holzer Tables 2, 3, and 4.

\begin{tabular}{lccc}
\hline Firing order & \multicolumn{3}{c}{ Values of torsional vibration amplitude from } \\
computerize Holzer table & \\
Frequency & $1148 \mathrm{vpm}$ & 2379 vpm & $4162 \mathrm{vpm}$ \\
\hline Cyl.1 & 0.683163744 & -0.36062981 & -3.164426946 \\
Cyl.5 & 0.14020083 & -0.37910345 & 3.024314267 \\
Cyl.3 & 0.457420354 & -0.62824225 & 0.639015657 \\
Cyl.6 & -0.03327014 & -0.11065208 & 1.290559567 \\
Cyl.2 & 0.585105961 & -0.55475307 & -1.8924842 \\
Cyl.4 & 0.306572499 & -0.56511671 & 2.745213832 \\
\hline
\end{tabular}

a cylinder reduces its contribution to the total gas pressure torque. The identification of the faulty cylinder may be achieved by analyzing the phases of the lowest three harmonic orders.

Figure 4 is drawn by reconstructing the pressure traces of the six cylinders in a sequence corresponding to the firing order (1-5-3-6-2-4) with engine operating under normal conditions. Figure 5 shows the lowest three harmonic orders of the measured speed, respecting the measured amplitudes and phases. It is seen that only for the expansion stroke of cylinder 5, all three harmonic curves have, simultaneously, a negative slope. In the phase-angle diagrams (Figure 5) of these orders, the resultant vector corresponding to the harmonic component of the measured speed is also represented (shown by arrow having magnitude equal to amplitude of vibration) is drawn by using data in Figure 6. One may see that, for each of the three considered orders, the vectors are pointing toward the group of cylinders that produces less work. The cylinder that is identified three times among the less productive cylinders is the faulty as shown in Figure 5.

\section{Method for Detecting Fault in Operating Engine}

Based on the Figures 2 and 5, the following method is developed.
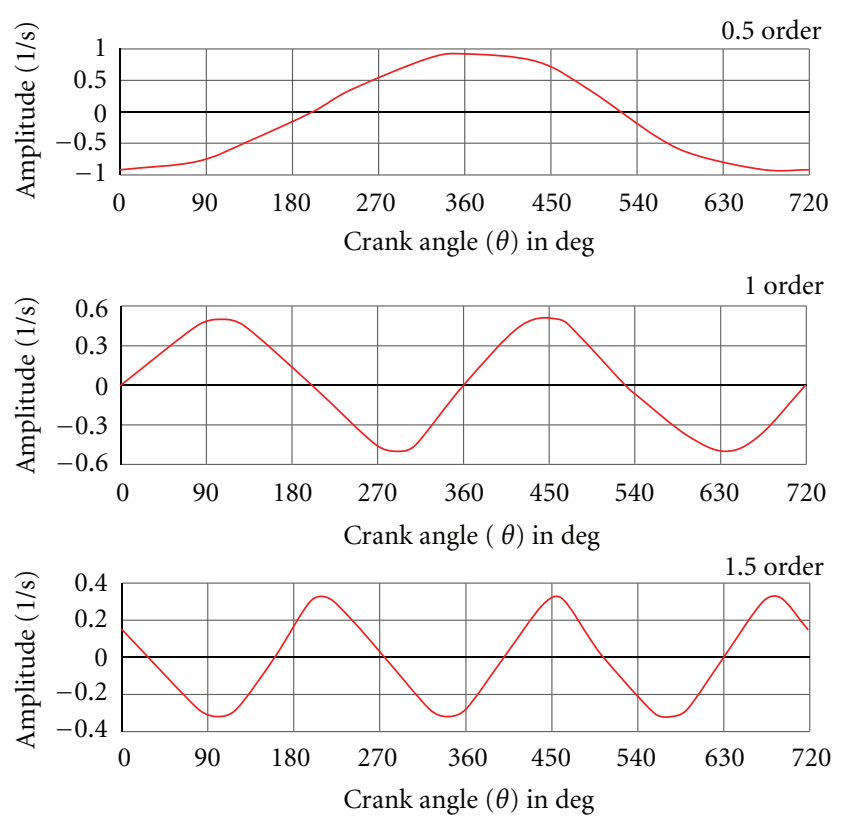

FIGURE 4: Detection of a faulty cylinder from the phases of the lowest three harmonic orders.

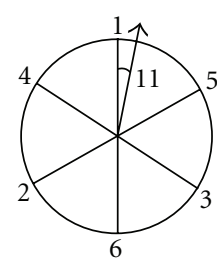

(a) $\theta=11^{\circ}$

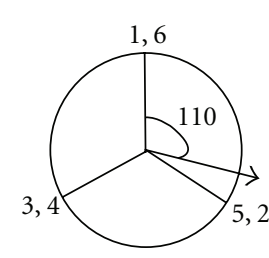

(b) $\theta=110^{\circ}$

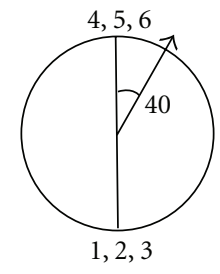

(c) $\theta=40^{\circ}$
Figure 5: Phase angle Diagram 0.5, 1, 1.5 order.

(1) The phase-angle diagrams, considering the firing order of the engine are drawn for the lowest three harmonic orders placing in the top dead centre (TDC) the cylinder that fires at $0^{\circ}$ in the considered cycle. 


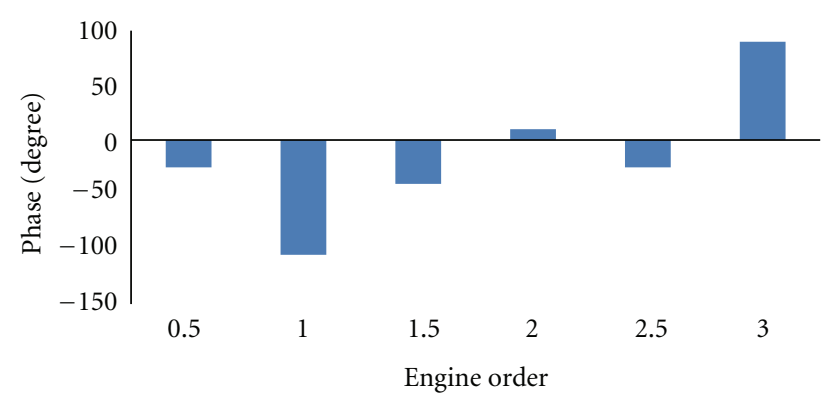

FIGURE 6: Phase versus engine order.

TABLE 6: Identification of the faulty cylinder from the position, in the phase-angle diagrams from Figure 2.

\begin{tabular}{lcccccc}
\hline \multirow{2}{K}{} & \multicolumn{6}{c}{ Cylinders } \\
& 1 & 5 & 3 & 6 & 2 & 4 \\
\hline 0.5 & - & - & & & & \\
1 & - & - & & - & - & \\
1.5 & & - & & - & & - \\
$I_{i}$ & 0 & -1 & 0 & 0 & 0 & 0 \\
\hline
\end{tabular}

TABLE 7: Identification of the faulty cylinder from the position, in the phase-angle diagrams Figure 5.

\begin{tabular}{lcccccr}
\hline \multirow{2}{K}{} & \multicolumn{5}{c}{ Cylinders } \\
& 1 & 5 & 3 & 6 & 2 & 4 \\
\hline 0.5 & - & - & & & & \\
1 & - & - & & - & - & \\
1.5 & & - & & - & & - \\
$I_{i}$ & 0 & -1 & 0 & 0 & 0 & 0 \\
\hline
\end{tabular}

(2) On these phase angle diagrams, the corresponding vectors of the measured speed are represented in a system of coordinate axes.

(3) The cylinders toward which the vectors are pointing are the less contributors and receive a "-" mark. If there are cylinders that receive a "-" mark for all three harmonic orders they are clearly identified as less contributors to the engine total output.

(4) This method is able to identify a faulty cylinder at very early stage, that is, before starting the engine manufacturing (Table 6) and as soon as its contribution reduces from rated value to zero with respect to the contribution of the other cylinders (Table 7).

\section{Conclusions}

Proposed methodology state the way of early fault detection in the operating diesel engine and Tables 6 and 7 shows validation of developed methodology. Here, torsional vibration amplitudes Table 2 are used to detect early fault in the operating diesel engine. In this paper, combination of mass torque and gas torque is used to map the fault. From this work it is found that the amplitudes of the lowest harmonic orders $(0.5,1$, and 1.5$)$ of the inertia masses and DFT of measured speed based on gas forces may be effectively used to map the fault. This method is capable to detect early faulty cylinders (which is now cylinder number 5) based on the phases of the lowest three harmonic as soon as its contribution starts to drop from rated value to zero due to its inertia forces as compared to the contribution of the other cylinders. This methodology can be also used for early fault diagnosis in the operating SI engine.

\section{References}

[1] E. J. Nestrides, A Handbook on Torsional Vibration, B.I.C.E.R.A, Research Library, Cambridge University Press, Cambridge, UK, 1958.

[2] J. Williams, "An overview of misfiring cylinder engine diagnostic techniques based on crankshaft angular velocity measurements," SAE Technical Paper 960039, 1996.

[3] K. S. Chen and T. Chang, "Crankshaft torsional and damping simulation-an update and correlation with test results," SAE Paper 861226, 1986.

[4] M. J. Van Nieuwstadt and I. V. Kolmanovsky, "Detecting and correcting cylinder imbalance in direct injection engines," ASME Journal of Dynamic Systems, Measurement and Control, vol. 123, no. 3, pp. 413-424, 2001.

[5] D. Taraza, N. Henein, and W. Bryzik, "Diesel engine diagnostics based on analysis of the crankshaft's speed variations," SAE Paper 982540, 1998.

[6] S. H. Gawande, L. G. Navale, M. R. Nandgaonkar D, S. Butala, and S. Kunamalla, "Detecting power imbalance in multicylinder inline diesel engine genst set," Journal of Electronic Science and Technology, vol. 8, no. 3, pp. 273-279, 2010.

[7] U. Kiencke and L. Nielson, Automotive Control Systems, for Engine, Driveline and Vehicle, Springer, Italy, 2005.

[8] U. Kiencke, "Engine misfire detection," Control Engineering Practice, vol. 7, no. 2, pp. 203-208, 1999.

[9] P. Boguś and J. Merkisz, "Misfire detection of locomotive diesel engine by non-linear analysis," Mechanical Systems and Signal Processing, vol. 19, no. 4, pp. 881-899, 2005.

[10] Y. W. Kim, G. Rizzoni, and Y. Y. Wang, "Design of an IC engine torque estimator using unknown input observer," Transactions of ASME Journal of Dynamic Systems Measurement and Control, vol. 121, no. 3, pp. 487-495, 1999.

[11] P. Charles, J. K. Sinha, F. Gu, L. Lidstone, and A. D. Ball, "Detecting the crankshaft torsional vibration of diesel engines for combustion related diagnosis," Journal of Sound and Vibration, vol. 321, no. 3-5, pp. 1171-1185, 2009.

[12] N. Cavina and F. Ponti, "Engine torque nonuniformity evaluation using instantaneous crankshaft speed signal," ASME Journal of Engineering for Gas Turbines and Power, vol. 125, no. 4, pp. 1050-1058, 2003.

[13] F. V. Tinaut, A. Melgar, H. Laget, and J. L. Domínguez, "Misfire and compression fault detection through the energy model," Mechanical Systems and Signal Processing, vol. 21, no. 3, pp. 1521-1535, 2007.

[14] S. H. Gawande, L. G. Navale, M. R. Nandgaonkar, and D. Butala, "Torsional frequency analysis of multi-cylinder inline diesel engine generator system," in Proceedings of the International Conference on Mechanical, Industrial, and Manufacturing Technologies (MIMT '10), pp. 519-524, ASME, January 2010.

[15] S. H. Gawande, L. G. Navale, M. R. Nandgaonkar, D. Butala, and S. Kunamalla, "Cylinder imbalance detection of six cylinder DI diesel engine using pressure variation," International Journal of Engineering Science and Technology, vol. 2, no. 4, pp. 433-441, 2010. 

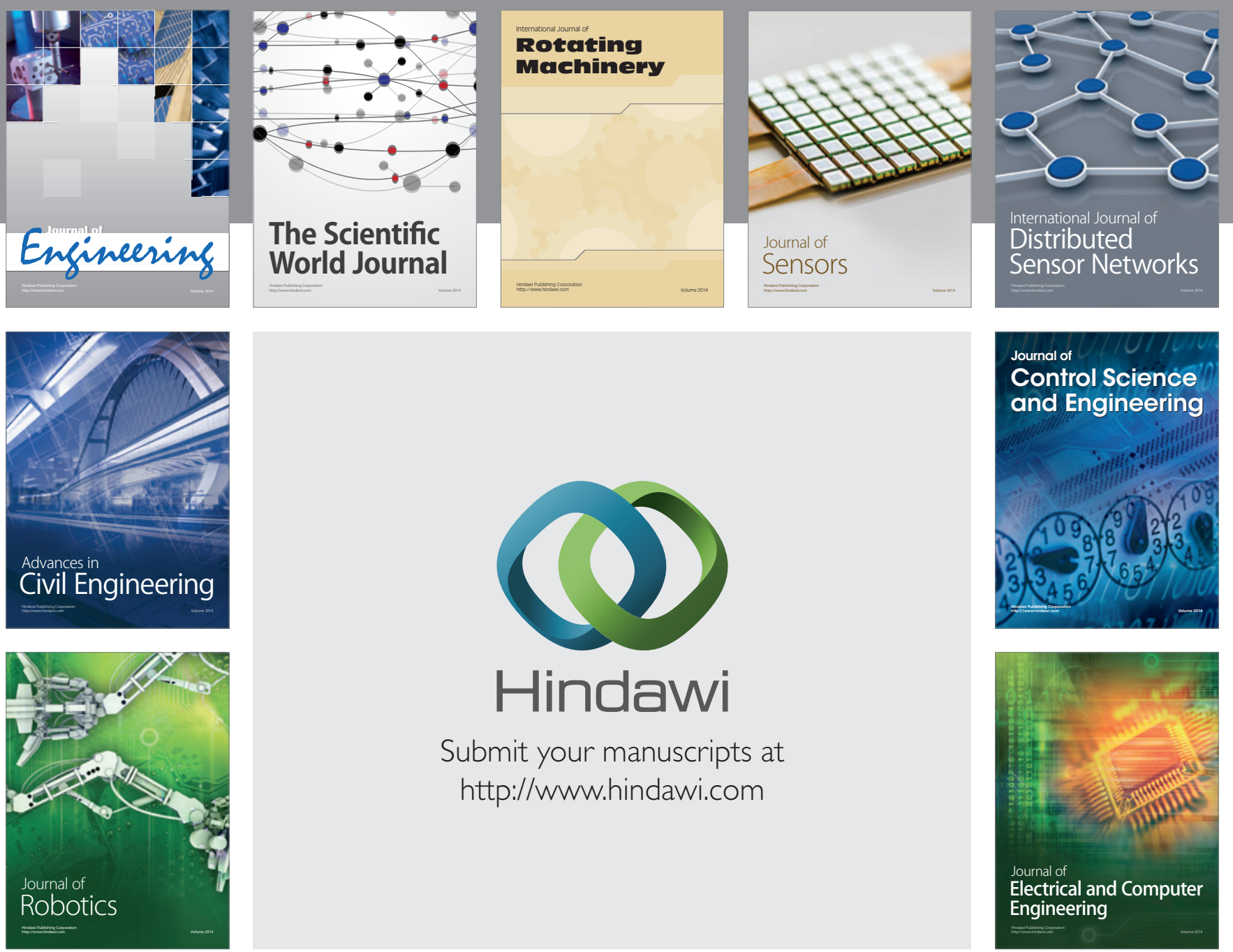

Submit your manuscripts at

http://www.hindawi.com
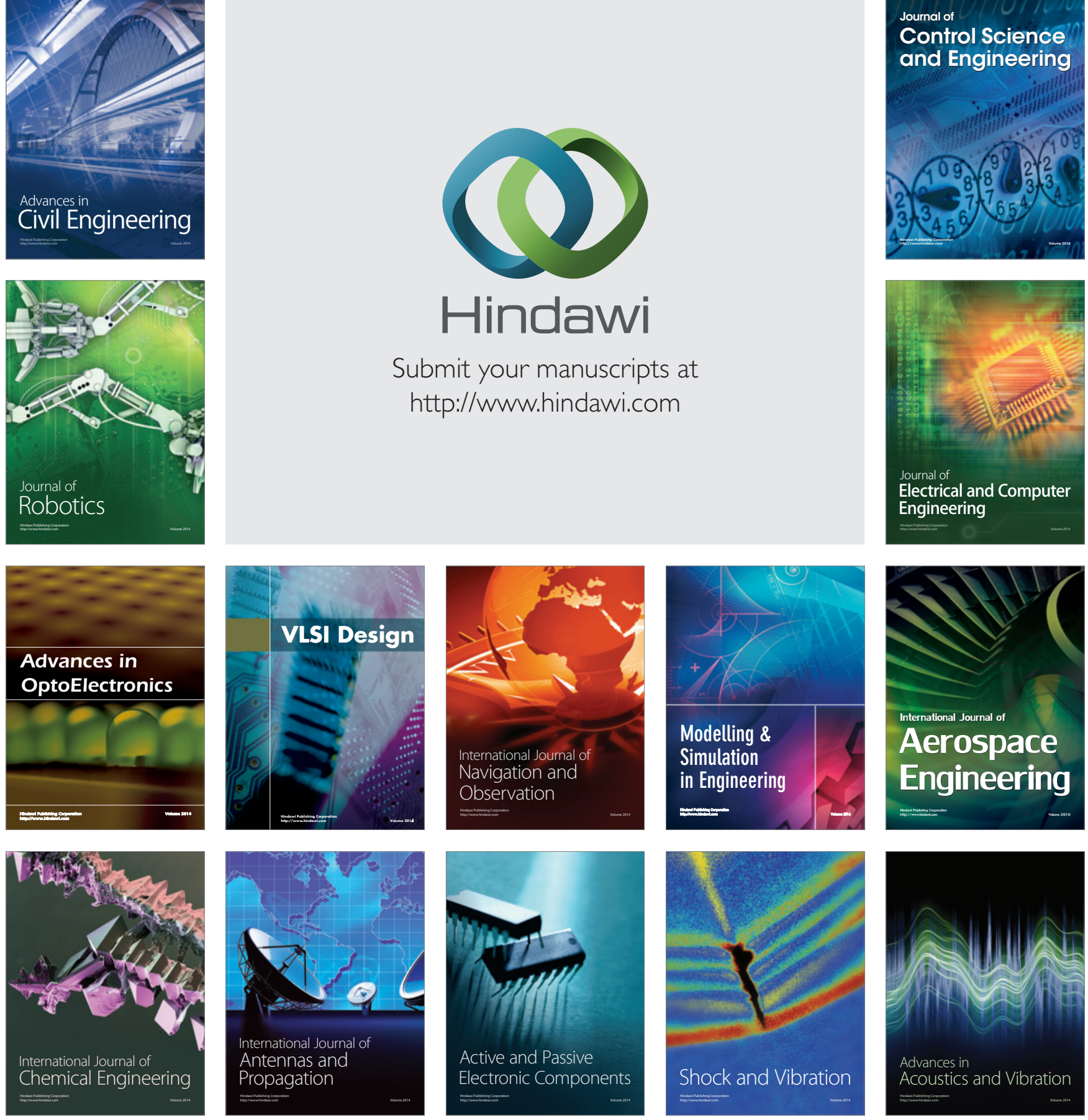